Das individuelle Ganze 
Angelika Ebrecht

\section{Das individuelle Ganze}

Zum Psychologismus der Lebensphilosophie

J. B. Metzlersche Verlagsbuchhandlung Stuttgart 


\section{Zur Autorin:}

Angelika Ebrecht, Dr.phil., Dipl.Psych.,Jahrgang 1957, studierte Germanistik, Politikwissenschaft und Psychologie. Derzeit arbeitet sie als Wissenschaftliche Assistentin für Politische Psychologie am Fachbereich Politikwissenschaft der Freien Universität Berlin.

Zugleich Dissertation im Fach Psychologie am Fachbereich Philosophie und Sozialwissenschaften I der Freien Universität Berlin (7/1990). GutachterInnen: Prof. Dr. Irmingard Staeuble, Prof. Dr. Anke Bennholdt-Thomsen und Prof. Dr. Klaus-Jürgen Bruder.

Die Deutsche Bibliothek - CIP-Einheitsaufnahme

\section{Ebrecht, Angelika:}

Das individuelle Ganze : zum Psychologismus der

Lebensphilosophie / Angelika Ebrecht. - Stuttgart : Metzler, 1992

Zugl.: Berlin, Freie Univ., Diss., 1990

ISBN 978-3-476-00792-6

ISBN 978-3-476-00792-6

ISBN 978-3-476-03390-1 (eBook)

DOI 10.1007/978-3-476-03390-1

Dieses Werk einschließlich aller seiner Teile ist urheberrechtlich geschützt. Jede Verwertung außerhalb der engen Grenzen des Urheberrechtsgesetzes ist ohne Zustimmung des Verlages unzulässig und strafbar. Das gilt insbesondere für Vervielfältigungen, Übersetzungen, Mikroverfilmungen und die Einspeicherung und Verarbeitung in elektronischen Systemen.

(C) 1991 Springer-Verlag GmbH Deutschland

Ursprünglich erschienen bei J. B. Metzlersche Verlagsbuchhandlung und Carl Ernst

Poeschel Verlag GmbH in Stuttgart 1991 


\section{Inhalt}

1. Einleitung $\ldots \ldots \ldots \ldots \ldots \ldots \ldots \ldots \ldots \ldots \ldots \ldots \ldots, 9$

\section{Krise, Kritik und Erlösungshoffnung}

2.1. Krisenbewußtsein und theoretische Grundhaltung der Lebensphilosophie

Theoriemode oder theoretische Neubesinnung ...... 21

Krise des bürgerlichen Selbstbewußtseins .......... 22

Subjektive Totalität als individuelle Ganzheit ....... 28

Ursprungssehnsucht und Widerstand ............ 31

2.2. Kulturelles Unbehagen, Kultur- und Technikkritik

Freud, Jaspers, Jünger, Rathenau, Simmel, Sombart, Spengler

Das Unbehagen in der Kultur ................ 38

Der kulturkritische Dualismus zwischen Gemeinschaft und Gesellschaft $\ldots \ldots \ldots \ldots \ldots \ldots \ldots \ldots \ldots \ldots . \quad 44$

Bedeutungsverschiebungen im Verhältnis von Kultur und Technik ........................... 48

Individualität, Leben und Ganzheit als Gegenbegriffe .. $\quad 53$

Radikalisierung des dualistischen Denkens und der

Technikkritik ............................ 54

2.3. Die Kritik an technischer und positivistischer Rationalität als Repräsentanten eines 'falschen Ganzen'

Bergson, Carnap, Driesch, Husserl, Kahler, Krieck, Schlick, WEBER

Wissenschaftsskepsis und Subjektverlust $\ldots \ldots \ldots \ldots \ldots .61$

Kritik der zweckrationalen Vernunft ............ 63

Positivistisches Einheitsdenken und metaphysische

Ganzheit ............................ $\quad 71$ 
2.4. Lebensphilosophischer Psychologismus als Ersatz von Vernunftsubjekt und Gesellschaft: Lebenswelt und

Weltanschauung als Individualitäten

Dilthey, Husserl, Simmel

Philosophie und Psychologie ................. 80

Vernunftentwicklung und lebensweltlicher Ursprungssinn $\quad 82$

Husserls Revision seiner Psychologismuskritik ....... 86

Der Psychologismus des Lebenswelt-Konzepts ....... 88

Lebenswelt und Weltanschauung ............... 94

2.5. Individualität und Autonomie:

Die ästhetische Psyche als Rettungsmodell

Dilthey, Heidegger, Simmel

Erkenntnistheoretische Verschiebung von Allgemeinheit 98

Heideggers Kritik an der lebensphilosophischen Ontologie $\quad 99$

Leben als Selbstzweck und Transzendenz ........... 102

Das prekäre individuelle Allgemeine .............. 105

Die individuelle Seelenganzheit als Kunstwerk ....... 109

2.6. Die naturphilosophische Tradition des Individualitätsund Freiheitsproblems

Kant, SCHELLING

Ästhetik und Naturphilosophie

Organismus und Kunstwerk zwischen Natur und Geist 122

Naturganzes und individueller Organismus ........ 126

Das organologische Problem individueller Freiheit .... 130

3. Die Psychologie des Lebendigen als Versuch einer Rettung des Ganzen ins Individuelle

3.1. Die Maschinentheorie des Lebens und die Frage nach der organischen Entwicklung

Bertalanffy, Darwin, Driesch, Haeckel, M.Hartmann, Loeb, Reinke, Raux, Schultz

Mechanismus versus Organismus .............. 137

Die Maschinentheorie des Lebens ............... 140

Kausalität und Substanz ...................... 143

Finalität, Teleologie und Organisation ........... 146 
3.2. Organische Ganzheit als natürliche Basis und Beginn individueller Freiheit

Das Freiheitsproblem in der Lebensphilosophie ...... 155

Drieschs Begriff der entelechialen Entwicklung ....... 156

Bergsons Begriff der organischen Dauer ........... 162

3.3. Natürliche Individualität als Grundlage des lebensphilosophischen Psychologismus: Das Leib-Seele-Problem

Natur und Freiheit ...................... 173

Drieschs Psychovitalismus .................... 174

Bergsons Psychologismus ..................... 180

3.4. Geist und Seelenleben: Zum Verhältnis von Rationalität, psychischer Natur und individueller Identität

Bergson, Driesch, Husserl

Innere Natur als Basis von Rationalität und

Selbstbewußtsein ......................... 191

Zum Begriff der Wesensschau bei Driesch und Husserl 194

Die Seele, das andere Ich ..................... 198

Das doppelte Ich bei Bergson ................. 204

3.5. Psychologie der Individualität:

Zeitliche Ganzheit und persönliche Identität als Freiheit, man selbst sein zu müssen

BERGSON, DRIESCH

Zeit, Freiheit und Identität ................. 210

Freiheit von der Zeit bei Driesch ............... 211

Bergsons »Erinnerung $\ldots \ldots \ldots \ldots \ldots \ldots \ldots \ldots \ldots . \quad 217$

3.6. Psychologie der Verneinung: Freiheit von sich selbst oder Freiheit des Selbstseins

Bergson, DrIESCH

Selbstsein und Freiheit als Konfliktbegriffe ........ 232

Freiheit des Neinsagens bei Driesch ............. 235

Bergsons Intuition als Verneinung der Realität ...... 242 
3.7. Geist gegen Seele: Die Absage an das individuelle Selbstsein als Verkehrung von Freiheit in Unfreiheit KLAGES

Technikkritik, Geistfeindschaft und Irrationalismus .... 254

Seelenganzheit, Ich und Selbstsein .............. 256

Leib und Seele .......................... 260

Erlebnis, Zeit und Raum ................... 261

Erlebnis, An-Schauung und Bild .............. 263

Subjekt und Objekt, Ferne und Nähe ........... 267

Wollen und Müssen ....................... 273

Wille und Verneinung .................... 277

\section{Die Selbstaufhebung des Individuellen im Ganzen}

4.1. Psychologie der Unfreiheit: Die Selbstaufgabe der Individualität EHRENFeLs, KRUeger, Volkelt

Die Wende zum fundamentalen Universalismus ...... 283

Die Herrschaft des Gefühlsganzen ............. 285

Methodische und inhaltliche Ganzheitsorientierung ... 290

Ganzheitspsychologie und Vitalismus ............ 292

Zwecklosigkeit und Ästhetisierung des Ganzen ....... 294

4.2. Universalismus, Selbstzerstörung und Zerstörung der anderen: Substitution von Individualität, Freiheit und Leben durch Führer, Blut und Rasse

Dietrich, Jaensch, Hitler, Krieck, Spann, Rosenberg

Individualität und Universalismus .............. 300

Technische Rationalität und fundamentaler

Irrationalismus .......................... 308

Das Überindividuum ...................... 313

\section{Rekapitulation und Aktualisierung}

Kultur und Natur ......................... 319

Die Modernität der Lebensphilosophie .............. 320

Die antimodernistischen Folgen der Lebensphilosophie .... 323

Die Aktualität der Lebensphilosophie .............. 325

Literaturverzeichnis ...................... 330 